\title{
Oxidation of limonene over molybdenum dioxide- containing nanoporous carbon catalysts as a simple effective method for the utilization of waste orange peels
}

\author{
Agnieszka Wróblewska ${ }^{1} \cdot$ Edyta Makuch $^{1}$ - Jacek Młodzik ${ }^{2}$. \\ Zvi C. Koren ${ }^{3} \cdot$ Beata Michalkiewicz ${ }^{2}$
}

Received: 22 June 2018/Accepted: 8 September 2018/Published online: 19 September 2018

(C) The Author(s) 2018

\begin{abstract}
A new method of the oxidation of natural limonene, obtained from waste orange peels, using relatively inexpensive $\mathrm{MoO}_{2}$-containing activated carbon catalysts is presented. The contents of molybdenum in the catalysts were equal to $0.68,1.32$, and $2.64 \mathrm{wt} \%$, and these new materials were investigated using various instrumental methods (ICP-AES, XRD, SEM, and GC), as well as liquid nitrogen sorption. The oxidation of limonene was performed separately with $\mathrm{H}_{2} \mathrm{O}_{2}$ and t-butyl hydroperoxide (TBHP) as the oxidants under the following conditions: temperature of $70{ }^{\circ} \mathrm{C}$, molar ratio of limonene/oxidant $=1: 2$, methanol concentration $95 \mathrm{wt} \%$, catalyst content $2.45 \mathrm{wt} \%$, and reaction times of $0.5-72 \mathrm{~h}$. All catalysts were active in the oxidation of limonene. With $\mathrm{H}_{2} \mathrm{O}_{2}$ as the oxidant, carveol (selectivity of 42-65 mol\%) and perillyl alcohol (selectivity of $10-30 \mathrm{~mol} \%$ ) were the main products of the limonene oxidation, and carvone and 1,2-epoxylimonene diol were by-products. For the oxidations with TBHP, the conversion of limonene was lower than with hydrogen peroxide. This new environmentally friendly method allows for the transformation of organic waste material into industrially important value-added products.
\end{abstract}

Keywords Limonene $\cdot$ Carvone $\cdot$ 1,2 Epoxylimonene diol $\cdot$ Activated carbon · Catalyst

Agnieszka Wróblewska

agnieszka.wroblewska@zut.edu.pl

1 Faculty of Chemical Technology and Engineering, Institute of Organic Chemical Technology, West Pomeranian University of Technology Szczecin, Pulaskiego 10, 70-322 Szczecin, Poland

2 Faculty of Chemical Technology and Engineering, Institute of Inorganic Chemical Technology and Environment Engineering, West Pomeranian University of Technology Szczecin, Pulaskiego 10, 70-322 Szczecin, Poland

3 Department of Chemical Engineering, Shenkar College of Engineering, Design and Art, 12 Anna Frank St, 52526 Ramat Gan, Israel 


\section{Introduction}

For centuries, terpenes have been utilized as components of fragrances in perfumery and cosmetics and also as food additives [1]. Moreover, terpenes have found therapeutic applications in medicine and have been reported to have significant antiinflammatory, antioxidant, antiviral, antimicrobial, anticancer and analgesic properties [2].

Terpenes form a large group of naturally occurring compounds that exist as the constituents of essential oils of several plants. Until now, more than 25,000 terpenes have been identified, some of them are repelling agents and protect plants from insects and animals [3]. Others prevent fungus, attract bees and other animals that carry the plant's pollen to other plants, can activate olfactory receptors, and generate flavor by activating taste receptors. Recently, there has been an increasing interest in the utilization of many monoterpenes in medicine and in studies on their molecular and cellular effects [4]. This interest is mainly connected with their properties, such as: high antitumor activity, commercial availability, low cost, oral bioavailability, and low toxicity [5].

A large group of terpenes, especially monoterpenes, can also be synthesized by synthetic routes from natural reactants obtained from plants [6, 7]. An example of this was previously described by us for the oxidation of R-(+)-limonene, obtained from waste orange peels, over heterogeneous catalysts, such as, titanium silicate [8-10] or active carbons impregnated with Fe metal ions [11-13].

Wróblewska [8] described preliminary studies on the epoxidation of limonene over two titanium silicate catalysts: TS-1 and Ti-SBA-15. The studies were performed in the temperature range of $0-120{ }^{\circ} \mathrm{C}$, for reaction times from 0.5 to $24 \mathrm{~h}$, and at the molar ratio of limonene $/ \mathrm{H}_{2} \mathrm{O}_{2}=1: 2$, solvent concentration of 80 , and $3 \mathrm{wt} \%$ catalyst content. Both tested catalysts were active in the process of epoxidation, but the mesoporous Ti-SBA-15 catalyst was the more active one. For both catalysts, the formation of carveol was observed but almost all of the carveol was converted to carvone, independent of the temperature and the reaction time. The increase in temperature and reaction time caused an increase in the amounts of these products of allylic oxidation position 6 . The next product was perillyl alcohol (a product of allylic oxidation at position 7), which was stable under the experimental conditions and its transformation to perillyl aldehyde was not detected. As in the case of carveol and carvone, the increase in temperature and reaction time caused an increase in the amount of this product. For carveol and perillyl alcohol, two possible transition states were proposed. Taking into account the size of the limonene molecule, the size of the pores of the catalysts, and the structures of the proposed transition states it was found that for the TS-1 catalyst, formation of perillyl alcohol proceeded inside the narrow pores. The ring of the limonene molecule is flexible and it can probably adopt a configuration in which this ring is very narrow and can enter into the TS-1 pores. However, the formation of carveol occurs on the outside surface of this catalyst. The narrow size of the pores of TS-1 ensures that further transformation of perillyl alcohol to perillyl aldehyde does not occur. It was assumed for the Ti-SBA-15 catalyst that allylic oxidation and 
oxidative dehydrogenation reactions can happen inside the pores and also on the outside surface of this catalyst.

Wróblewska et al. [9] described detailed studies on the oxidation of limonene over the TS-1 catalyst. The influence of temperature, molar ratio of limonene/ hydrogen peroxide, methanol concentration, catalyst content and reaction time were studied. The investigations showed that the process of limonene epoxidation is very complicated and it is difficult to establish such conditions for this process at which only one product is obtained. It turned out that the most influential properties on the course of the oxidation were temperature and the reaction time. The product of the epoxidation at positions 1-2 was formed with the highest selectivity only at the lowest temperature; the increase in temperature hindered the epoxidation process and privileged the oxidation at the 6-7 position. Moreover, for the short reaction time the main products were perillyl alcohol and 1,2-epoxylimonene diol (product of hydration of epoxide ring in 1,2-epoxylimone). The prolongation of the reaction time changes the main directions of the oxidation because the next product was formed-carveol-and stability of the epoxide ring at the 1-2 position was increased. In addition, this work also proposed that carvone can be formed not only by the oxidative dehydrogenation of carveol to carvone but also directly by the oxidation of limonene.

Gawarecka et al. [10] investigated the oxidation of limonene over Ti-MCM-41 and Ti-MWW catalysts with tert-butyl hydroperoxide (TBHP). The process was complicated as it was not possible to produce 1,2-epoxylimonene with high selectivity, and therefore the research was focused on obtaining high selectivities of perillyl alcohol and carveol. Over the Ti-MCM-41 catalyst (at the best conditions) conversion of limonene was $95 \mathrm{~mol} \%$ and yields of products were $57 \mathrm{~mol} \%$ perillyl alcohol and $28 \mathrm{~mol} \%$ carveol. With the Ti-MWW catalyst, conversion of limonene was $59 \mathrm{~mol} \%$, and the yield of perillyl alcohol was $39 \mathrm{~mol} \%$ and for carveol $14 \mathrm{~mol} \%$. It seemed that for Ti-MWW the limonene molecules had more difficult access to the active centers compared to Ti-MCM-41; this was connected with the smaller pore size and the availability of active titanium centers in the former catalyst.

Młodzik et al. [11] described the oxidation of limonene over Fe/EuroPh catalysts with different concentrations of Fe $(0.68,1.32$ and $2.64 \mathrm{wt} \%)$. The studies were carried out with hydrogen peroxide and TBHP as the oxidants. All catalysts were active in the oxidation of limonene with these oxidants, and the main product was perillyl alcohol. For the oxidation with hydrogen peroxide formation of 1,2epoxylimonene and its diol were also detected. During studies with TBHP, 1,2epoxylimonene was formed only for the catalyst with $2.64 \mathrm{wt} \% \mathrm{Fe}$ content. For the catalysts with the lowest Fe content, independent of the oxidant used, formation of carvone was observed. It was assumed in this work that carvone was formed as a result of direct oxidation of limonene at the 6-position. Moreover, the formation of carveol was not observed. The re-used catalysts considerably lost their activities, and it was most apparent for oxidations with TBHP.

Wróblewska et al. [12] described the oxidation of limonene with hydrogen peroxide as the oxidant over Fe/nanoporous carbon catalysts obtained from molasses with $\mathrm{Fe}$ contents the same as above. The main products were 1,2- 
epoxylimonene and its diol, carveol and perillyl alcohol. Over the catalyst with 0.68 wt $\% \mathrm{Fe}$, the main product carveol was formed (selectivity of 97-99\%). Formation of carvone was not observed, but small amounts of 1,2-epoxylimonene were detected. Over the catalyst with $1.32 \mathrm{wt} \% \mathrm{Fe}$, the main product was perillyl alcohol with a selectivity of $49-56 \mathrm{~mol} \%$ for the short reaction time. For longer reaction times, 1,2-epoxylimonene diol was the dominant product (selectivity of 63-74 mol\%), and, simultaneously, carveol was also formed in small quantities. Over the catalyst with $2.64 \mathrm{wt} \% \mathrm{Fe}$, the main product was perillyl alcohol (selectivity of 61-77 mol\%), and the second product was 1,2-epoxylimonene diol (selectivity of $23-36 \mathrm{~mol} \%$ ). Also in this work the mechanism of oxidation of limonene over carbon catalysts containing $\mathrm{Fe}$ was proposed.

Wróblewska et al. [13] presented studies on the oxidation of limonene over the same Fe-containing catalysts obtained from molasses, as described above, but with TBHP as the oxidizing agent. The catalysts containing 0.68 and $1.32 \mathrm{wt} \% \mathrm{Fe}$ showed that nearly the only product of the limonene oxidation was carveol (selectivity of 96-98 mol\%). For the catalyst with $2.64 \mathrm{wt} \% \mathrm{Fe}$ the main product was 1,2-epoxylimonene (selectivity up to $64 \mathrm{~mol} \%$ ) and perillyl alcohol (selectivity up to $75 \mathrm{~mol} \%$ ).

In the oxidations described in the above works [8-13], the usual main products were perillyl alcohol and carveol. These oxidation methods allow for a decrease in the large-scale production costs of these compounds because they use relatively inexpensive raw materials, very often of natural origin, and are performed at mild processing conditions. According to these investigations, utilization of titanium silicate catalysts and catalysts on the basis of EuroPh activated carbon containing $\mathrm{Fe}$, seems to be the most beneficial, taking into account the cost of the catalyst production as the method of preparation of carbon catalysts from molasses is very complicated and expensive.

The latest directions in the studies on the process of limonene epoxidation can be as follows: searching for new more efficient titanium silicate catalysts, development of simple and inexpensive catalysts on the basis of activated carbon with various metal atoms (for example $\mathrm{Mo}$, $\mathrm{Ti}$ or $\mathrm{Cu}$ ), utilization of porous materials of natural origin as catalysts or utilization of new oxidizing agents that do not need catalyst applications. These research goals on limonene oxidation should allow for an increase in selectivity of perillyl alcohol or carveol, and an increase in selectivity of other valuable products of this process (1,2-epoxylimonene or 1-2,8-9-diepoxylimonene), and for decreasing the costs of the process by utilization of, for example, only an oxidizing agent without the catalyst.

Regarding titanium silicate catalysts, epoxidation of limonene by TBHP over the new Ti-SBA-16 catalysts obtained by post grafting methods was described by Charbonneau et al. [14]. These studies showed that the 3D pore structure of the SBA-16 material favors reactants and products mass transfer as compared with the 2D pore structure of SBA-15. The main product of oxidation was 1,2-epoxylimone oxide (selectivity of $79 \%$, and conversion of limonene reaching $80 \%$ ).

The production of diepoxide (1-2,8-9-diepoxide) of limonene during catalyst-free epoxidation of limonene was described by Charbonneau et al. [15]. In this process, the oxidizing agent was dimethyl dioxirane (formed in the in situ reaction of acetone 
with oxone). The yield of diepoxide reached $97 \%$ with the conversion of limonene of about $100 \%$. The advantage of this process was in performing the reaction at room temperature, but it was not eco-friendly due to the utilization of acetone as the solvent. A more advantageous scheme for the production of the diepoxide seems to be in the presence of a catalyst of natural origin - montmorillonite. The preliminary study over this porous material was presented by Malko et al. [16] and showed the possibility to obtain the diepoxide with the selectivity of about $48 \mathrm{~mol} \%$, but this work needs further development by studying the influence of other appropriate parameters.

Simple and inexpensive catalysts on the basis of activated carbon catalyst with various metal atoms (for example $\mathrm{Mo}$, $\mathrm{Ti}$ or $\mathrm{Cu}$ ) were not previously described in the literature.

Among the various applications of perillyl alcohol and carveol, special attention has been paid to those uses in medicine. Perillyl alcohol has been shown to be efficacious against the formation and progression of a variety of cancers, such as, colon, skin, head and neck [17-23]. This terpene compound was also used in clinical tests on humans; for example, it is the effective chemotherapeutic agent in curing pancreatic cancers [23-25], in neuro-oncology on patients with anaplastic oligodendroglioma [26], and in inhibiting lung cancer growths [27, 28]. Carveol also shows pharmacological activities [29] and it was used in the therapy of pancreatic and breast cancers [30].

Molybdenum-containing catalysts for limonene oxidation were described by some authors. They used very sophisticated materials, such as, polybenzimidazolesupported Mo(VI) [31], dioxo( $\mu$-oxo)molybdenum(VI) dimer [32], dichlorodioxomolybdenum(VI)-pyrazolylpyridine [33], indenyl molybdenum(II) tricarbonyl complex [34], molybdenum peroxo complexes [35] or Keggin heteropolycompounds [36]. However, catalysts in the form of $\mathrm{MoO}_{2}$, supported on the activated carbon EuroPh carrier, have not been previously described in the literature.

As we described above, the development of simple and inexpensive catalysts is essential for the industrial production of carveol and perillyl alcohol from biomass. In this paper we present a new, inexpensive and environmentally-friendly method of perillyl alcohol and carveol production from natural limonene obtained from waste orange peels. According to our knowledge, simple molybdenum catalysts, namely $\mathrm{MoO}_{2}$, supported on the activated carbon EuroPh, were applied for the limonene oxidation for the first time in the current study. The purpose was the development of a new production method for these two very valuable compounds, which can be used in the pharmaceutical, cosmetic, and food industries mentioned above. In this work we also propose the mechanism of limonene oxidation to carveol and perillyl alcohol in the presence of $\mathrm{MoO}_{2}$ catalysts supported on the EuroPh activated carbon material. 


\section{Materials and methods}

\section{Catalysts preparation}

The catalysts used in this work were prepared by impregnation of EuroPh (EP) - a commercial activated carbon (kindly supplied by Gryfskand, Poland)-with an aqueous solution of $\left(\mathrm{NH}_{4}\right)_{6} \mathrm{Mo}_{7} \mathrm{O}_{24} \cdot 4 \mathrm{H}_{2} \mathrm{O}$ for the molybdenum precursor. The impregnated sample was dried at $100{ }^{\circ} \mathrm{C}$ for $1 \mathrm{~h}$, and subsequently calcined in a tube furnace at $550{ }^{\circ} \mathrm{C}$ for $14 \mathrm{~h}$. More details about impregnation were presented in our previous work [37].

The Mo content was estimated by the inductively coupled plasma atomic emission spectrophotometry (ICP-AES) method. The XRD spectra were measured with the PANalytical Empyrean X-ray diffractometer. The SEM pictures were obtained using the Hitachi SU8020 Ultra-High Resolution Field Emission Scanning Electron Microscope (UHR FE-SEM)) with three detectors: the Secondary Electron (SE) detector, a photo-diode-backscattered electron (PDBSE) detector and Energy Dispersed Spectroscopy (EDS) detector.

PDBSE gives visual information based on gray-scale intensity between chemical phases. The amount of electrons backscattered depends on the atomic number. A particle consisting of an element of higher atomic number is significantly brighter than a particle of an element of lower atomic number. A contrast between phases of different atomic numbers is observed in the backscattered electron image.

The EDS detector is able to detect elements with atomic number greater than six. The elemental composition of a sample is determined using the characteristic X-ray spectrum of the specimen being investigated. The elemental analysis was performed in a "spot mode",

Nitrogen sorption at $77 \mathrm{~K}$ was utilized for specific surface area and pore volume estimations (Quadrasorb SI-Quantachrome Instruments). The specific surface area $\left(\mathrm{S}_{\mathrm{BET}}\right)$ was calculated on the basis of $\mathrm{N}_{2}$ sorption by the BET method. The micropore volume (Vmic)-pore diameter lower than $2 \mathrm{~nm}$-was estimated utilizing the DFT method. The total pore volume $\left(\mathrm{V}_{\text {tot }}\right)$ was derived from the amount of nitrogen adsorption at a relative pressure close to 1 , assuming that the pores were totally filled with the sorbate.

\section{Limonene oxidation method}

The oxidation of limonene was performed at $70{ }^{\circ} \mathrm{C}$, for the reaction times from 0.5 to $72 \mathrm{~h}$, molar ratio of limonene $/ \mathrm{H}_{2} \mathrm{O}_{2}$ or limonene/TBHP $=1: 2$, methanol concentration $95 \mathrm{wt} \%$ and the catalyst content in the reaction mixture of 2.45 $w t \%$. Limonene, with a purity $97 \%$, was obtained from waste orange peels by the simple distillation procedure. The detailed data about this method of producing natural limonene was presented in our previous work [10]. The process of oxidation of limonene was performed in a glass reactor with the capacity of $25 \mathrm{~cm}^{3}$, equipped with a reflux condenser, a thermometer and a magnetic stirrer. The progress of the reaction was examined after the following reaction times (in $\mathrm{h}$ ): $0.5,1,2,3,4,5,12$, 
24, 36, 48 and 72. Samples taken at the different reaction times were analyzed by the GC-method on a Focus apparatus equipped with a flame-ionization detector and fitted with the Restek Rtx-WAX capillary column filled with polyethylene glycol at the condition presented in our previous work [11]. The mass balance and the main functions describing the process were calculated in the same manner as was described in our previous work [11].

\section{Results and discussion}

The contents of the molybdenum in the catalysts were equal to $0.68,1.32,2.64 \mathrm{wt} \%$, and these materials were denoted as $\mathrm{XMo} / \mathrm{EP}$, where $\mathrm{X}$ is the Mo content.

The XRD patterns of the commercial activated carbon (EP) used as a support and the molybdenum-containing catalysts (Mo/EP) are depicted in Fig. 1. There were only two peaks at about 23 and 43 of the $2 \theta$ angle in the XRD pattern of the support corresponding to the (002) and (101) planes of the hexagonal graphite (JCPDS, 75-1621). The peaks are very broad because of random turbostratic stacking of a limited number of layers. These peaks almost disappeared after molybdenum impregnation, but new peaks coinciding with those of monoclinic $\mathrm{MoO}_{2}$ (JCPDS: 32-0671) were observed. After calcination in nitrogen the $\mathrm{MoO}_{2}$ was formed. As expected, the intensity of the signals corresponding to $\mathrm{MoO}_{2}$ depended on the molybdenum content, and, thus, the higher the concentration the greater the intensity of the peaks. The sizes of $\mathrm{MoO}_{2}$ crystallites were estimated by the Scherrer method [11]. The signal was disrupted by a very small and broad peak of the support but the sizes of the crystallites can be approximately estimated, and these sizes were about 50-60 nm regardless of the Mo concentration.

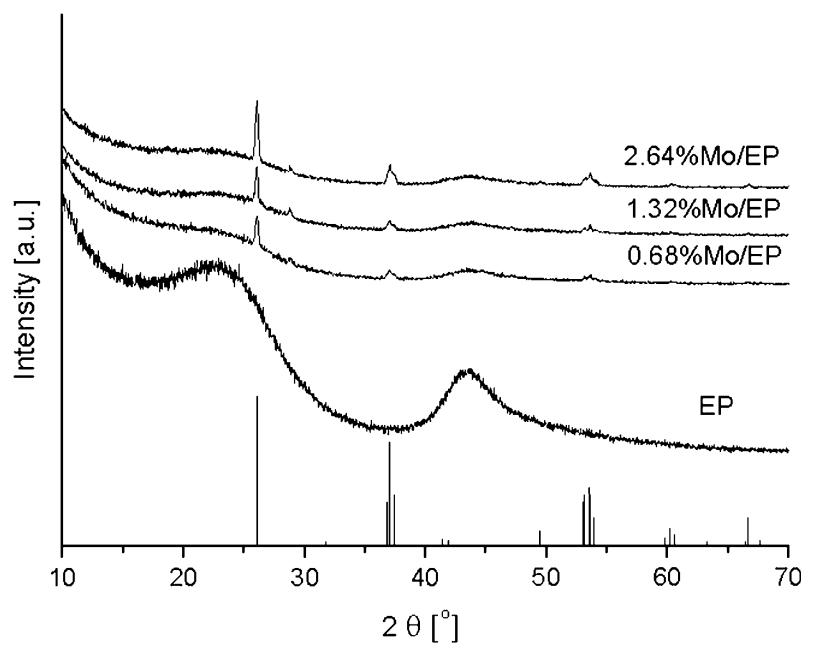

Fig. 1 XRD patterns of the EuroPh activated carbon (EP) and Mo/EP catalysts with different Mo content, vertical lines- $\mathrm{MoO}_{2}$ according JCPDS: 32-0671 


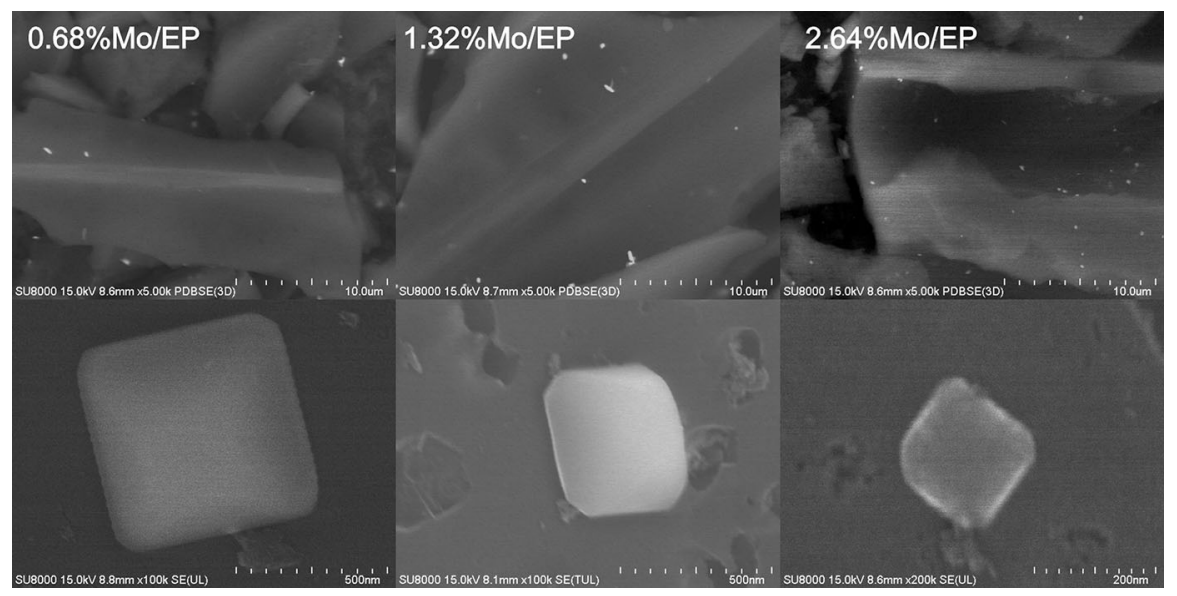

Fig. 2 FE-SEM pictures of the EuroPh activated carbon (EP) supported molybdenum catalysts with different Mo content made by utilization of the PDBSE detector

The SEM images of the catalysts are shown in Fig. 2 and these pictures were produced by use of the PDBSE detector. Generally, the BSE image is used to illustrate the distribution of heavier metals present on the surface. The presence of bright particles sticking to the surface of the support was observed, which revealed the presence of $\mathrm{MoO}_{2}$ particles randomly distributed on the surface. At a low magnification $(\times 5000)$ different concentrations of Mo were observed, and even at this magnification, the differences in the sizes of the $\mathrm{MoO}_{2}$ particles can be observed. At higher magnifications $(\times 100,000$ and $\times 200,000)$ the differences were clearly seen. It was noticed that, in general, the higher the Mo concentration, the smaller the $\mathrm{MoO}_{2}$ particles that were produced. The average sizes of the particles were 700,250 and $195 \mathrm{~nm}$ for the $0.68 \% \mathrm{Mo} / \mathrm{EP}, 1.32 \% \mathrm{Mo} / \mathrm{EP}, 2.64 \mathrm{Mo} \% /$ EP catalysts.

The molybdenum content on the surface of the support was investigated by the EDS method. It was found that the Mo concentrations on the surface were higher than in the bulk and were equal to $1.3,5.3,7.0 \mathrm{wt} \%$ for the $0.68 \% \mathrm{Mo} / \mathrm{EP}, 1.32 \% \mathrm{Mo} /$ $\mathrm{EP}, 2.64 \% \mathrm{Mo} / \mathrm{EP}$ catalysts.

Table 1 shows the results obtained by nitrogen sorption measurements. The increase in the content of Mo results in a decrease in total pore volume and micropore volume. The influence of Mo content on the specific surface area was indistinct. Values of $\mathrm{S}_{\mathrm{BET}}$ varied between 1384 and 1456. Similarly, the influence of

Table 1 Specific surface area, total pore volume and micropore volume of the support and catalysts

\begin{tabular}{llll}
\hline Name & $\mathrm{S}_{\mathrm{BET}}\left(\mathrm{m}^{2} / \mathrm{g}\right)$ & $\mathrm{V}_{\text {tot }}$ & $\mathrm{V}_{\text {micro }}$ \\
\hline $\mathrm{EP}$ & 1452 & 0.816 & 0.021 \\
$0.68 \% \mathrm{Mo} / \mathrm{EP}$ & 1456 & 0.808 & 0.015 \\
$1.32 \% \mathrm{Mo} / \mathrm{EP}$ & 1384 & 0.770 & 0.016 \\
$2.64 \% \mathrm{Mo} / \mathrm{EP}$ & 1425 & 0.797 & 0.011 \\
\hline
\end{tabular}


molybdenum content on distribution of pores (Fig. 3) was indistinguishable. The pore size distributions of the support and of the catalyst containing $1.32 \mathrm{wt} \%$ of molybdenum were similar. The pore size distribution of catalysts with extreme molybdenum contents were similar as well. The reason for the lack of correlation can be a change of $\mathrm{MoO}_{2}$ particle size with the Mo content. It can be concluded that two factors influenced the textural properties: Mo content and $\mathrm{MoO}_{2}$ particle size.

The irregular change in pore size distribution observed in Fig. 3 can be explained in this way. Adding dopants to the starting materials can cause an increase or decrease of pore diameter. Pores can be blocked and a decrease of pore diameter is observed. New pores can be built and then an increase of pore diameter is observed. In pristine samples pores of about $2 \mathrm{~nm}$ are dominant. Small amounts of Fe $(0.68$ $\mathrm{wt} \%$ ) blocked small pores (about $2 \mathrm{~nm}$ ) but simultaneously bigger pores are built and thus pores of about $2.5 \mathrm{~nm}$ are dominant. The addition of $1.32 \mathrm{wt} \% \mathrm{Fe}$ did not effectively block small pores (and hence diameter is at about $2 \mathrm{~nm}$ again). However, greater amounts of $\mathrm{Fe}(2.64 \mathrm{wt} \%)$ blocked small pores again and favor building of bigger pores to a diameter of about $2.5 \mathrm{~nm}$. As we showed in Fig. 2, the molybdenum particle size on the surface depended on the Fe load. This makes the changes of the pore diameter more complicated and irregular.

We used the $\mathrm{N}_{2}$ at $77 \mathrm{~K}$ model on carbon (slit pore, QSDFT equilibrium model) for the pore distribution calculation because the fitting error was the lowest, and was equal to $0.200 \%$.

The results of the studies on the oxidation of limonene are presented in Figs. 4 (for $\mathrm{H}_{2} \mathrm{O}_{2}$ ) and 5 (for TBHP).

Using hydrogen peroxide as the oxidant, the conversion of limonene increased with increasing reaction times, from 0.5 to $72 \mathrm{~h}$, for all the catalysts and amounted to the following values: $0-31 \mathrm{~mol} \%$ for $0.68 \% \mathrm{Mo} / \mathrm{EP} ; 0-43 \mathrm{~mol} \%$ for $1.32 \% \mathrm{Mo} /$ $\mathrm{EP}$; and $0-71 \mathrm{~mol} \%$ for $2.64 \% \mathrm{Mo} / \mathrm{EP}$.

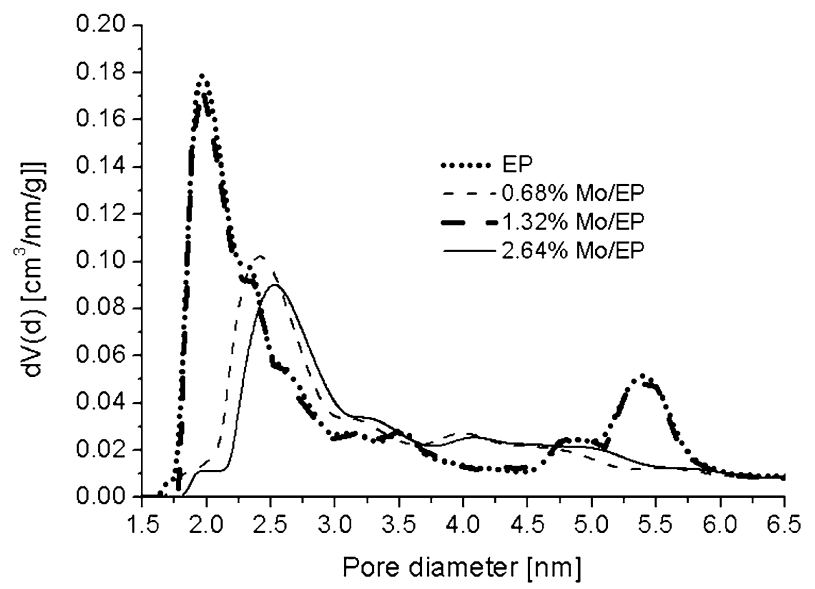

Fig. 3 Pore size distribution of the EuroPh activated carbon (EP) and Mo/EP catalysts with different Mo content estimated on the basis of $\mathrm{N}_{2}$ adsorption at $77 \mathrm{~K}$ and DFT method 

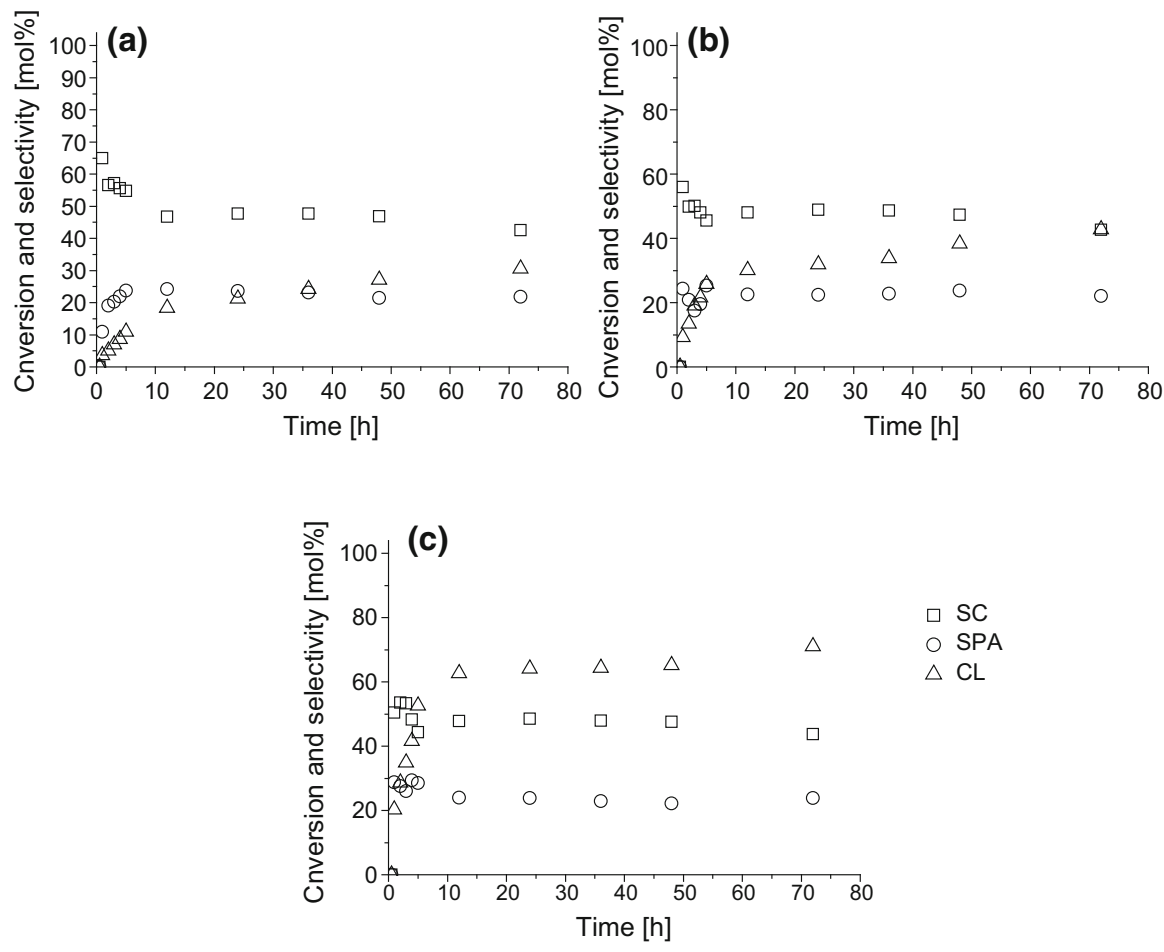

Fig. 4 The limonene conversion and selectivities of the products of limonene oxidation over $0.68 \% \mathrm{Mo} /$ $\mathrm{EP}(\mathbf{a}), 1.32 \% \mathrm{Mo} / \mathrm{EP}(\mathbf{b})$ and $2.64 \% \mathrm{Mo} / \mathrm{EP}$ (c) catalysts (studies with $\mathrm{H}_{2} \mathrm{O}_{2}$ ), $S C$ selectivity to carveol, $S P A$ selectivity to perillyl alcohol, $C L$ limonene conversion. Experimental conditions: temperature of $70{ }^{\circ} \mathrm{C}$, solvent methanol $(95 \mathrm{wt} \%)$, molar ratio of limonene/TBHP $=1: 2$, catalyst content in the reaction mixture of $2.45 \mathrm{wt} \%$

For the $0.68 \% \mathrm{Mo} / \mathrm{EP}$ catalyst the highest increase in limonene conversion is observed for reaction times up to $12 \mathrm{~h}$. For longer reaction times, the conversion of limonene grows on average by $3 \mathrm{~mol} \%$ per $12 \mathrm{~h}$. Taking into account the value of this function, the simulated oxidation time should not surpass $48 \mathrm{~h}$. During the tests over the $1.32 \% \mathrm{Mo} / \mathrm{EP}$ catalyst, the conversion of limonene changed in a very similar way (with slightly higher rates). Also in the case of this catalyst, the maximum oxidation time should not exceed $48 \mathrm{~h}$. Over the $2.64 \% \mathrm{Mo} / \mathrm{EP}$ catalyst, a reaction time sufficient to achieve high conversion values of limonene is $12 \mathrm{~h}$. For longer reaction times, no significant changes in the values of this function are observed. Considering that the microporous size for the $2.64 \% \mathrm{Mo} / \mathrm{EP}$ catalyst $\left(0.011 \mathrm{~m} \mathrm{~m}^{3} / \mathrm{g}\right)$ is significantly smaller than for the other catalysts and for the EP support, it is likely that the micropores of this catalyst are harder to access for the reacting molecules and the reaction mainly occurs on the catalyst surface. This is also favored by the significant Mo content on the surface of this catalyst (7 wt \%) and a small particle size of $\mathrm{MoO}_{2}$ of $195 \mathrm{~nm}$, so that the reactant molecules have easier access to the active centers of Mo. 
Carveol selectivity for all studied catalysts for the reaction time of $0.5 \mathrm{~h}$ amounted to $0 \mathrm{~mol} \%$ (reaction did not proceed for this reaction time) and, for subsequent reaction times, decreased from 65 to $43 \mathrm{~mol} \%$ for $0.68 \% \mathrm{Mo} / \mathrm{EP}$. For the other two catalysts this property decreased to the same value but from a selectivity of $56 \mathrm{~mol} \%$ (for $1.32 \% \mathrm{Mo} / \mathrm{EP}$ ) and from $50 \mathrm{~mol} \%$ (for $2.64 \% \mathrm{Mo} / \mathrm{EP}$ ).

Perillyl alcohol selectivity changed slightly for all studied catalysts and amounted to $11-24 \mathrm{~mol} \%$ (for the $0.68 \% \mathrm{Mo} / \mathrm{EP}$ catalyst), $24-18 \mathrm{~mol} \%$ (for $1.32 \% \mathrm{Mo} / \mathrm{EP}$ ) and $29-24 \mathrm{~mol} \%$ (for $2.64 \% \mathrm{Mo} / \mathrm{EP}$ ).

Carvone and 1,2-epoxylimonene diol were also identified in the products of the limonene oxidation, and they were both detected after a reaction time of $1 \mathrm{~h}$ over all studied catalysts. The carvone selectivity changed from about 20-24 to 28-31 mol\% for all catalysts. The studies showed that all the 1,2-epoxylimonene formed was transformed to its diol. However, the formation of 1,2-epoxylimonene diol for the $0.68 \% \mathrm{Mo} / \mathrm{EP}$ catalyst was observed only after $12 \mathrm{~h}$ of reaction, while for the next two catalysts, after $2 \mathrm{~h}$. Selectivities of 1,2-epoxylimonene diol were considerably lower than for the other products and amounted to 3-12 mol\% for all catalysts.

It was found that for the oxidation of limonene with hydrogen peroxide the selectivity of carveol and perillyl alcohol did not depend on the Mo content, pore volume, and particle size of $\mathrm{MoO}_{2}$ of the catalysts. However, the conversion of limonene and the selectivity of 1,2-epoxylimonene diol depended on these parameters.

For the oxidations with TBHP (Fig. 5) the conversion of limonene increased in the range of the reaction time from 0.5 to $72 \mathrm{~h}$ as follows: $1-29 \mathrm{~mol} \%$ (for the $0.68 \% \mathrm{Mo} / \mathrm{EP}$ catalyst), $2-69 \mathrm{~mol} \%$ (for $1.32 \% \mathrm{Mo} / \mathrm{EP}$ ) and $4-9 \mathrm{~mol} \%$ (for $2.64 \% \mathrm{Mo} / \mathrm{EP})$. The comparison of the conversions achieved with the hydrogen peroxide and TBHP shows that only over the catalyst with the lowest Mo content $(0.68 \% \mathrm{Mo} / \mathrm{EP})$ the conversions of limonene were similar. For the second catalyst, the conversion of limonene was 1.6 times, and for the third 1.4 times, higher for TBHP than for hydrogen peroxide. Moreover, in contrast to the use of hydrogen peroxide, a constant increase in the conversion of limonene with extended reaction time was observed over all three catalysts. The use of a very long reaction time (72 h) is therefore advantageous in the case of limonene oxidation with TBHP. This is most likely because the TBHP reacts more easily with the Mo centers located on the surface of the catalyst than in the pores, therefore increasing the amount of Mo on the catalyst surface will favor the limonene oxidation reaction. At the same time, the t-butyl alcohol formed with TBHP will increase the solubility of both substrates and products, and thus the reaction will be faster. In addition, because the reaction occurs on the surface of the catalyst, the steric effects associated with the size of the reactant molecules will not be as important as in the case of reactions occurring only in the pores of the catalyst.

These studies also showed that it was possible to obtain only carveol as the product of limonene oxidation under the following conditions: for $0.68 \% \mathrm{Mo} / \mathrm{EP}$ catalysts for the reaction times $1-12 \mathrm{~h}$, for $1.32 \% \mathrm{Mo} / \mathrm{EP}$ for $2-4 \mathrm{~h}$, and for $2.46 \mathrm{Mo} \% / \mathrm{EP}$ for $2-4 \mathrm{~h}$. For longer reaction times carveol was the main, but not the sole product. Selectivity of this compound decreased from 100 to $66 \mathrm{~mol} \%$ (for 

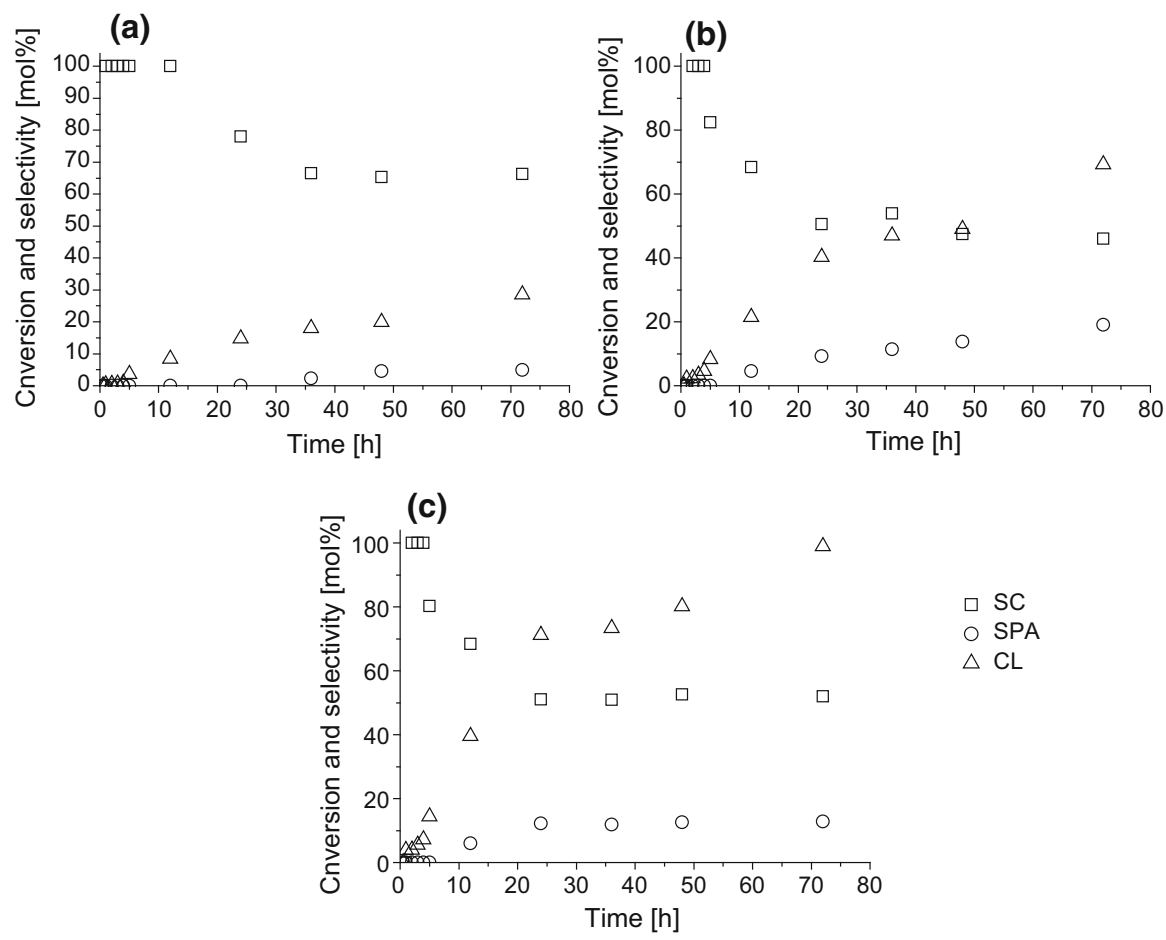

Fig. 5 The limonene conversion and selectivities of the products of limonene oxidation over $0.68 \% \mathrm{Mo} /$ $\mathrm{EP}(\mathbf{a}), 1.32 \% \mathrm{Mo} / \mathrm{EP}(\mathbf{b})$ and $2.64 \% \mathrm{Mo} / \mathrm{EP}$ (c) catalysts (studies with TBHP), SC selectivity to carveol, $S P A$ selectivity to perillyl alcohol, $C L$ limonene conversion. Experimental conditions: temperature of $70{ }^{\circ} \mathrm{C}$, solvent methanol $(95 \mathrm{wt} \%)$, molar ratio of limonene/TBHP $=1: 2$, catalyst content in the reaction mixture of $2.45 \mathrm{wt} \%$

$0.68 \% \mathrm{Mo} / \mathrm{EP}$ ), to $46 \mathrm{~mol} \%$ (for $1.32 \% \mathrm{Mo} / \mathrm{EP}$ ) and to $52 \mathrm{~mol} \%$ (for $2.46 \mathrm{Mo} \% / \mathrm{EP}$ ). The selectivity of perillyl alcohol was lower than if $\mathrm{H}_{2} \mathrm{O}_{2}$ was used as the oxidant (selectivity to perillyl alcohol 2-19 mol\%). This product started to form for the first catalyst after $36 \mathrm{~h}$ and for the next two catalysts after $12 \mathrm{~h}$. Selectivity of carvone changed from 22 to $32 \mathrm{~mol} \%$, but this product started to form for the first catalyst after $24 \mathrm{~h}$ and for the next two catalysts after $12 \mathrm{~h}$. 1,2-epoxylimonene was not formed over the first catalyst, but over the second two it was formed after $5 \mathrm{~h}$ with the selectivity of $4-11 \mathrm{~mol} \%$. It showed that in oxidations with TBHP, the formation of this compound needed longer reaction times. Simultaneously, the epoxide ring was stable (lack of water molecules) and formation of 1,2epoxylimonene was not observed.

It was found that for studies on the oxidation of limonene with TBHP that the conversion of limonene and selectivities of all products (carveol, perillyl alcohol, carvone and 1,2-epoxylimonen) depended on the Mo content, pore volume, and particle size of $\mathrm{MoO}_{2}$ of the catalysts.

A comparison of the results obtained for the oxidation of limonene with hydrogen peroxide and TBHP indicates that the oxidation of limonene mostly occurs on the 
surface of the catalysts, and the most easily formed reaction product is carveol, secondly carvone and perillyl alcohol. However, the most difficult one is the epoxidation of the double bond in positions 1-2 in the limonene molecule. The fact that the oxidation of limonene occurs mostly on the surface of the catalysts is evidenced by the results for the $2.64 \mathrm{Mo} / \mathrm{EP}$ catalyst. For this material, characterized by the highest $\mathrm{Mo}$ content, the smallest $\mathrm{MoO}_{2}$ particles and the smallest pore volume, the best oxidation results were obtained-the highest conversion of limonene and high selectivities of carveol and perillyl alcohol. Considering the low temperature of the oxidation process, a radical mechanism seems less likely for this process. On the basis of the literature data [8-37], the following possible ionic mechanism $[8,35,36]$ for the oxidation of limonene with hydrogen peroxide to carveol can be proposed:
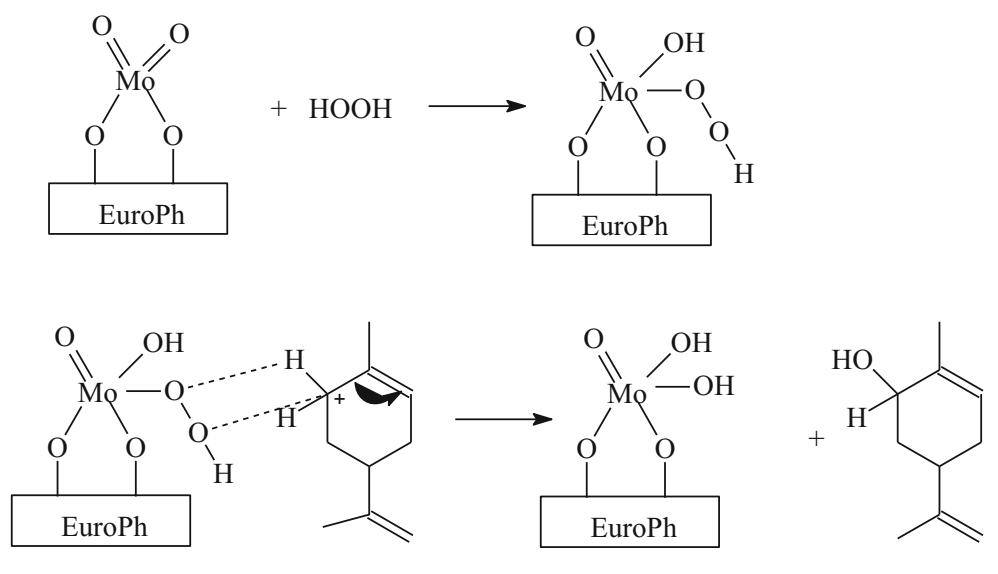

limonene

carveol

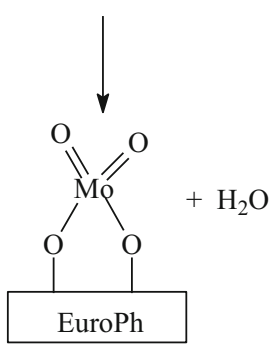

The first step of this mechanism proceeds with the transfer of a hydrogen peroxide proton to a terminal oxygen atom of one of the MoO groups together with the coordination of the $-\mathrm{OOH}$ group to the Lewis acidic center (Mo) and formation of the peroxo intermediate. In the limonene molecule, formation of the allylic oxidation product (carveol or perillyl alcohol) is a result of a shift of electrons in the direction of the double bond in limonene and creation of a positive charge on the $\mathrm{C}$ atom in the 6-position (in case of carveol formation) or the C-7 atom (in case of perillyl alcohol formation), and simultaneously the interaction between the active peroxo intermediate and the C-6 or C-7 atom. 
For perillyl alcohol formation the creation of positive charge on the C-7 atom can be presented as follows [8]:

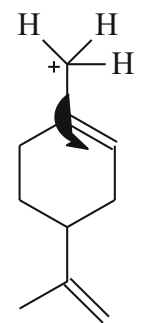

However, the results obtained for perillyl alcohol are significantly worse than for carveol, which indicates that creation of a positive charge on the $\mathrm{C}-7$ atom is more difficult to form than on the C- 6 atom, and from here the formation of the peroxo intermediate by coordination of the $-\mathrm{OOH}$ group to the Lewis acidic center (Mo) is harder in the case of perillyl alcohol formation. The next steps in the production of perillyl alcohol are similar to those for carveol formation.

For the oxidation of limonene with TBHP, which can be represented as ROOH, with $\mathrm{R}=\left(\mathrm{CH}_{3}\right)_{3}$, a very similar peroxo intermediate can be formed, as represented below:

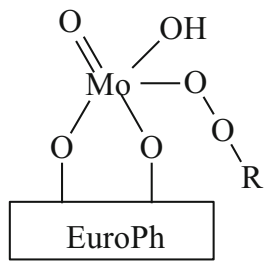

The subsequent steps for the formation of carveol or perillyl alcohol are also similar to that of hydrogen peroxide oxidation of limonene. The interaction between the limonene molecule and this peroxo intermediate can be illustrated as follows:

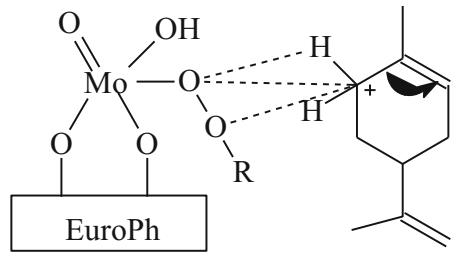

limonene

A further comparison of the results obtained for hydrogen peroxide and TBHP as oxidants showed that higher conversions of limonene over $1.32 \% \mathrm{Mo} / \mathrm{EP}$ and $2.64 \% \mathrm{Mo} / \mathrm{EP}$ catalysts and selectivity of carveol were obtained with TBHP. This indicates that the steric hindrance associated with the presence of the t-butyl group 
in the peroxo intermediate did not have a large influence on the course of the process. On the other hand, it did have an effect on the formation of other reaction products, such as carvone, perillyl alcohol and 1,2-epoxylimonene. These compounds formed only for longer reaction times: 1,2-epoxylimonene after $5 \mathrm{~h}$, and carvone after $12 \mathrm{~h}$ (for the last two catalysts).

During the process, the catalysts were partially deactivated. We investigated the reason for this and we conjecture that the pores were blocked. After desorption, the catalysts were active again. In order to explain this problem and find the best solution more experiments are needed.

\section{Conclusions}

We presented a new method of perillyl alcohol and carveol production by the oxidation of limonene obtained from waste orange peels by $\mathrm{H}_{2} \mathrm{O}_{2}$ or TBHP in the presence of activated carbon catalysts containing molybdenum in the form of $\mathrm{MoO}_{2}$. This group of catalysts has not been previously utilized in such a process. These catalysts were very effective in the oxidation of limonene, and carveol and perillyl alcohol were obtained as the main products. Carveol can be obtained as the only product if TBHP was applied as the oxidant for relatively short reaction times (up to $5 \mathrm{~h}$ ). However, taking into account the low conversion of limonene, the possibility of obtaining only carveol in the post reaction mixtures needs further studies, specifically the influence of relevant process parameters with various solvents should be developed. These Mo/EP catalysts offer new and cost-effective means for perillyl alcohol and carveol production under relatively mild conditions (low temperature and atmospheric pressure). For this purpose, a low-cost commercially available EuroPh activated carbon was utilized. The catalysts that were previously used (e.g. TS-1, TiSBA-15, Ti-MCM-41 and Ti-MWW) are relatively expensive because of hydrothermal synthesis. A Fe/nanoporous carbon catalyst is also expensive because its synthesis is complicated and moreover requires use of HF, which is hazardous.

This current work shows that the use of a relatively inexpensive catalyst in the form of commercial readily available activated carbon modified with Mo allows for similar results to those obtained on synthetically obtained titanium silicates, but which are much more expensive catalysts. This new environmentally-friendly method allows for the transformation of biomass waste into value-added products.

Open Access This article is distributed under the terms of the Creative Commons Attribution 4.0 International License (http://creativecommons.org/licenses/by/4.0/), which permits unrestricted use, distribution, and reproduction in any medium, provided you give appropriate credit to the original author(s) and the source, provide a link to the Creative Commons license, and indicate if changes were made.

\section{References}

1. Berger RG (2007) Flavours and fragrances: chemistry, bioprocessing and sustainability. Springer, New York

2. Marcinkowski D, Wałęsa-Chorab M, Patroniak V, Kubicki M, Kąłdziołka G, Michalkiewicz B (2014) New J Chem 38:604-610 
3. Harrewijn P, van Oosten AM, Piron PG (2000) Natural terpenoids as messengers. Springer, Netherlands

4. Lozon Y, Sultan A, Lansdell S (2016) Eur J Pharm 776:44-51

5. Crowell PL (1997) Breast Cancer Res Treat 46:191-197

6. Pena A, Veiga S, Sapelli M, Martinez N, Marquez V, Dellacassa E, Bussi J (2012) Reac Kinet Mech Cat 107:263-273

7. Lima FL, Cardozo-Filho L, Arrovo PA, Marquez-Alvarez H, Antunes OAC (2005) Reac Kinet Catal Lett 84:69-77

8. Wróblewska A (2014) Molecules 19:19907-19922

9. Wróblewska A, Makuch E, Miądlicki P (2016) Catal Today 268:121-129

10. Gawarecka A, Wróblewska A (2018) Reac Kinet Mech Cat 124:523-543

11. Młodzik J, Wróblewska A, Makuch E, Wróbel RJ, Michalkiewicz B (2016) Catal Today 268:111-120

12. Wróblewska A, Makuch E, Młodzik J, Koren ZC, Michalkiewicz B (2017) Catal Lett 147:150-160

13. Wróblewska A, Makuch E, Młodzik J, Michalkiewicz B (2017) Green Process Synth 6:397-401

14. Charbonneau L, Kaliaguine S (2017) Appl Catal A 533:1-8

15. Charbonneau L, Foster X, Zhan D, Kaliaguine S (2018) ACS Sustain Chem Eng 6:5115-5121

16. Malko M, Antosik AK, Wróblewska A, Czech Z, Wilpiszewska K, Miądlicki P, Michalkiewicz B (2017) Pol J Chem Technol 4:50-58

17. Gupta A, Stratton SP, Myrdal PB (2005) J Pharm Biomed Anal 37:447-452

18. Gupta A, Myrdal PB (2004) Inter J Pharm 269:373-383

19. Peffley DM, Sharma C, Hentosh P, Buechler RD (2007) Arch Biochem Biophys 465:266-273

20. Elegbede JA, Flores R, Wang RC (2003) Life Sci 73:2831-2840

21. Stark MJ, Burke YD, McKinzi JH, Ayoubi AS, Crowell PL (1995) Cancer Lett 96:15-21

22. Chen J, Lu M, Jing Y, Dong J (2006) Bioorg Med Chem 14:6539-6547

23. Sobral MV, Xavier AL, Lima TC, De Sousa DP (2014) Sci World J. https://doi.org/10.1155/2014/ 953451

24. Crowell PL, Ayoubi AS, Burke YD (1996) Adv Exp Med Biol 401:131-135

25. Matos JM, Schmidt CM, Thomas HJ, Cummings OW, Wiebke EA, Madura JA, Patrick LJ, Crowell PL (2008) J Surg Res 147:194-199

26. Da Fonesca CO, Masini M, Futuro D, Caetano R, Gattass CR (2016) Surg Neurol 66:611-615

27. Xu M, Floyd HS, Greth SM, Chang WC, Lohman K, Stoyanova R, Kucera GL, Kute TE, Willingham MC, Miller MS (2004) Toxic Appl Pharm 195:232-246

28. Yeruwa L, Pierre KJ, Elegbede A, Wang RC, Carper SW (2007) Cancer Lett 257:216-226

29. Jaafari A, Tilaoui M, Mouse HA, M'bark LA, Aboufatima R, Chait A, Lepoivre M, Zyad A (2012) Braz J Pharm 22(3):534-540

30. Ni X, Suhail MM, Yang Q, Cao QA, Fung KM, Postier RG, Woolley C, Young G, Zhang J, Lin HK, Compl BMC (2012) Alter Med 12(253):1-14

31. Ambroziak K, Mbeleck R, Saha B, Sherrington DC (2010) Int J Chem Reactor Eng 8:1-13

32. Pereira CCL, Balula SS, Paz FA, Valente AA, Pillinger M, Klinowski J, Gonçalves IS (2007) Ing Chem 46:8508-8510

33. Amarante TR, Neves P, Paz FA, Valente AA, Pillinger M, Gonçalves IS (2014) Dalton Trans 43:6059-6069

34. Abrantes M, Bruno SM, Tome C, Pillinger M, Goncalves IS, Valente AA (2011) Catal Commun 15:64-67

35. Srivastava S, Nicholas KM (1996) Chem Commun 20:2335-2336

36. Casuscelli SG, Crivello ME, Perez CF, Ghione G, Herrero ER, Pizzio LR, Vázquez PG, Cáceres CV, Blanco MN (2004) Appl Catal A 274:115-122

37. Michalkiewicz B, Sreńscek-Nazzal J, Tabero P, Grzmil B, Narkiewicz U (2008) Chem Pap 62:106-113 